\title{
POSTPARTUM MASTITIS IN THE BREASTFEEDING WOMEN AND ANTIMICROBIAL RESISTANCE OF RESPONSIBLE PATHOGENS IN UKRAINE: RESULTS A MULTICENTER STUDY
}

DOI: 10.36740/WLek202005111

\author{
Aidyn G. Salmanov', Serhii E. Savchenko', Kyrylo Chaika', Alla D. Vitiuk', Iana Ruban', Olena A. Dyndar², \\ Dmytro Zhelezov ${ }^{3}$, Ludmila Vorobey ${ }^{1}$, Liudmula M. Semeniuk ${ }^{4}$, Natalia V. Hetsko ${ }^{5}$, Olga V. Tsmur ${ }^{5}$, \\ Lidiya V. Suslikova' ${ }^{1}$, Tetiana R. Nykoniuk², Yelizaveta Ye. Shunko' ${ }^{1}$, Halyna V. Beketova', Lyudmila V. Manzhula², \\ Valentyna V. Kurochka², Esmira R. Abbasova ${ }^{6}$ \\ 'SHUPYK NATIONAL MEDICAL ACADEMY OF POSTGRADUATE EDUCATION, KYIV, UKRAINE \\ 2BOGOMOLETS NATIONAL MEDICAL UNIVERSITY, KYIV, UKRAINE \\ ${ }^{3}$ ODESA NATIONAL MEDICAL UNIVERSITY, ODESA, UKRAINE \\ ${ }^{4}$ UKRAINIAN SCIENTIFIC AND PRACTICAL CENTER OF ENDOCRINE SURGERY, ENDOCRINE TRANSPLANTATION OF ORGANS AND TISSUES OF THE \\ MINISTRY OF HEALTH OF UKRAINE, KYIV, UKRAINE \\ SUZHHOROD NATIONAL UNIVERSITY, UZHHOROD, UKRAINE \\ 6BROVARSKA MULTIDISCIPLINARY DISTRICT HOSPITAL, BROVARY, UKRAINE
}

\begin{abstract}
The aim: To obtain the prevalence of mastitis in the breastfeeding women and antimicrobial resistance of responsible pathogens in Ukraine.

Materials and methods: A retrospective multicenter cohort study was based on surveillance data for Postpartum Mastitis and included 18,427 breastfeeding women's who gave birth in 11 regional hospitals of Ukraine.

Results: $22.6 \%$ breastfeeding women's were found to have breast infections. Among these patients, $11.6 \%$ breast abscess and $88.4 \%$ mastitis were observed. 0 f the total cases breast infections, $74.8 \%$ were detected after hospital discharge. The rate of healthcare-associated mastitis was $8.6 \%$. The predominant pathogens were: Staphylococcus aureus (23.6\%), Escherichia coli (19.4\%), Enterobacter spp. (11.9\%), Staphylococcus epidermidis (10.7\%), Klebsiella spp. (8.7\%), Pseudomonas aeruginosa (4.8\%), Enterococcus faecalis (4.8\%), and Proteus mirabilis (4.6\%). The overall proportion of methicillin-resistance was observed in $27.9 \%$ of S. aureus (MRSA) and 24.3\% of S. epidermidis (MRSE). 0 f the total methicillin-resistance strains, $74.8 \%$ of MRSA and $82.1 \%$ of MRSE is community-acquired, were detected after hospital discharge. Vancomycin resistance was observed in $9.2 \%$ of isolated enterococci. Carbapenem resistance was identified in $7.3 \%$ of P.aeruginosa isolates. Resistance to third-generation cephalosporins was observed in $8.8 \%$ Klebsiella spp. and E.coli $9.1 \%$ isolates.

Conclusions: Mastitis in the breastfeeding women in Ukraine requires medical attention it is common, and a lot of cases are caused by pathogens resistant to antibiotics. Optimizing the management and empirical antimicrobial therapy may reduce the burden of mastitis, but prevention is the key element.
\end{abstract}

KEY WORDS: breastfeeding women; postpartum mastitis; breast abscess; pathogens; antimicrobial resistance

\section{INTRODUCTION}

Postpartum mastitis is one of the most common pyoinflammatory infections that occur in the breastfeeding women, and can progress from the infective mastitis to a breast abscess [1,2]. In breastfeeding women's, mastitis or breast abscessis one of the main medical causes of early weaning [1-4], and is one of the diseases with highest economic impact and, a major welfare concern [5].

Guidelines for treatment recommend appropriate antibiotic therapy of breast abscesses $[1,6,7]$. Early treatment with an appropriate antibiotic is necessary to prevent complications of infection [8]. Knowledge on the antimicrobial susceptibility status of responsible pathogens is important for better management of postpartum infections [4]. The lack of this information prompts the empiric use of broad-spectrum antibiotics giving rise to a frequent therapeutic failure.

To identify postpartum mastitis prevention targets and reduce thus disparities between countries, ongoing surveillance is necessary. However, the epidemiology of mastitis in breastfeeding women in Ukraine and associated treatment outcomes are not well studied. National network for the surveillance of antimicrobial resistance is not in Ukraine $[9,10]$. Postpartum mastitis problems experienced by Ukrainian breastfeeding women's have not been reported previously. 


\section{THE AIM}

The aim of this study was to obtain the prevalence of mastitis in the breastfeeding women and antimicrobial resistance of responsible pathogens in Ukraine.

\section{MATERIALS AND METHODS}

A retrospective cohort study was based on surveillance data for Postpartum Mastitis and included 18,427 breastfeeding women's who gave birth (vaginal delivery or cesarean section) in 11 regional (tertiary) women's hospitals of Ukraine between January 1st, 2015 and December 31st, 2017. These hospitals provide care to individuals living within its catchment area (total 2,108,241 women's) and regularly take referrals from other (primary and secondary) hospitals. We have included women's hospitals that are similar in terms of medical equipment, personnel, and laboratory facilities. The hospitals had 1236 beds. All participating hospitals were required to have at least one full-time infection-control professional, a clinical microbiology laboratory with the capacity to process cultures. The follow-up of each patient was continued 30 days ( 1 month).

Breast infections (breast abscess or mastitis) based on the definition used by the Centers for Disease Control and Prevention's National Nosocomial Infection Surveillance system (CDC/NHSN) [11]. A breast abscess or mastitis must meet at least 1 of the following criteria: (1) Patient has a positive culture of affected breast tissue or fluid obtained by incision and drainage or needle aspiration; (2) Patient has a breast abscess or other evidence of infection seen during a surgical operation or histopathologic examination; (3) Patient has fever $\left(>38^{\circ} \mathrm{C}\right)$ and local inflammation of the breast and physician diagnosis of breast abscess. Cases of breast abscesses or mastitis were classified into mutually exclusive groups comprised of either community-acquired or healthcare-associated infection. Cases of breast abscesses or mastitis that occurs within 7 days after childbirth considered health care associated.

The WHO's breastfeeding definitions were used in this study. Exclusive breastfeeding was defined as "breast milk (including milk expressed or from a wet nurse), oral rehydration

salt (ORS), drops, and syrups (vitamins, minerals, medicines)". Predominant breastfeeding was defined as "breast milk (including milk expressed or from a wet nurse) as the predominant source of nourishment and certain liquids (water and water-based drinks, fruit juice), ritual fluids and ORS, drops or syrups (vitamins, minerals, medicines)".

In this study, we analyzed the inpatient data and ambulatory medical records to identify postpartum mastitis and describe the epidemiology of these infections. To be included in the study, women must have chosen to breastfeed (with or without food supplements). Breastfeeding women's who were local residents, had living infants, were within 1 month postpartum, and had a singleton child were recruited into the study. Women's who were local residents, had living infants, were within 1 month postpartum, and had a singleton child were recruited into the study. Mothers were excluded if they were not a local resident of the selected regions. Participants were followed up during the 30 days postpartum. Information on infant feeding practices was collected at baseline and each follow-up visit. Full-text ambulatory medical records and relevant hospital records were reviewed for the 30-day postpartum period for a breastfeeding women's. All free-text notes were reviewed, and encounters for which the principal focus was the postpartum infection were identified. A standard data collection form was created to extract demographic and clinical data, microbiology (isolated pathogens and their antibiograms) and outcome information from routine patient records. Trained nurses and infection control professionals collected the data using structured questionnaires adapted from based on the definition used by CDC/NHSN on breast abscesses or mastitis. The data were conducted during 1 month (the first 4 weeks) postpartum, and information on were conducted during 1 month (the first 4 weeks) postpartum, and information on sociodemographic characteristics and lactation problems was collected at this time.

Infection rates for the entire study population of postpartum women were extrapolated by standard methods from the estimated infection rates for the sample of individual medical records and microbiologic laboratory records of specimens obtained from the breast.

We analyzed breast milk samples from breastfeeding women's in the context of a study about microbiology of postpartum mastitis and antimicrobial resistance of responsible pathogens. Milk samples were obtained from women with clinical symptoms of infectious mastitis. Breastmilk culture was obtained by manually collecting a clean catch sample in a sterile container (i.e. a small amount of initially expressed milk is discarded to avoid contamination of the sample with skin flora, and subsequent milk is expressed in a sterile container, being careful not to touch the inside of the container). The nipple was cleaned before to collection may further reduce skin contamination and minimise false-positive culture results.

All isolates from breast abscesses or mastitis cases was sent to microbiology laboratory for identification and antimicrobial resistance testing. Microbial isolates were identified using standard microbiological techniques, including automated microbiology testing (Vitek-2; bioMe'rieux, Marcy l'Etoile, France), and antibiotic susceptibility testing was performed by using the disk diffusion method (Kirby - Bauer antibiotic testing). Isolates were categorized as susceptible or resistant by Clinical and Laboratory Standards Institute criteria (CLSI). Strains in the intermediate range were classified as resistant for data analysis.

The Shupyk National Medical Academy of Postgraduate Education (Kyiv, Ukraine) ethics committee approved the waiver of informed consent to participate in this study due to its retrospective design. All patient data were anonymised prior to the analysis.

The Prevalence of postpartum mastitis was reported as the percentage of the total number of breastfeeding women's. Cases of postpartum mastitis were analysed by type of infection (community-acquired and healthcare-associated 
Table I. Characteristics of breastfeeding women with mastitis in Ukraine $(\mathrm{P}<0.05)$.

\begin{tabular}{|c|c|c|c|c|c|}
\hline \multirow[t]{2}{*}{ Characteristics } & \multicolumn{2}{|c|}{$\begin{array}{l}\text { Total cohort } \\
(\mathrm{n}=\mathbf{1 8 , 4 2 7})\end{array}$} & \multicolumn{2}{|c|}{$\begin{array}{c}\text { Mastitis } \\
(\mathrm{n}=\mathbf{4 1 7 2})\end{array}$} & \multirow{2}{*}{$\begin{array}{c}\text { Incidence } \\
\text { of mastitis } \\
{\left[95 \% \mathrm{Cl}^{a}\right]}\end{array}$} \\
\hline & $\mathbf{n}$ & $\%$ & $\mathbf{n}$ & $\%$ & \\
\hline Age (years, mean, SD $)$ & 25.2 & & 23.1 & & \\
\hline \multicolumn{6}{|l|}{ Age category $^{c}$} \\
\hline$\leq 18$ & 872 & 4.7 & 321 & 36.8 & $35.2-38.4$ \\
\hline $18-24$ & 7921 & 43.0 & 1732 & 21.9 & $21.4-22.4$ \\
\hline $25-34$ & 6788 & 36.8 & 1286 & 18.9 & $18.4-19.4$ \\
\hline $35-44$ & 2381 & 12.9 & 677 & 28.4 & $27.5-29.3$ \\
\hline$\geq 45$ & 465 & 2.7 & 156 & 33.5 & $31.3-35.7$ \\
\hline \multicolumn{6}{|l|}{ Mode of delivery } \\
\hline Vaginal & 15,588 & 84.6 & 2359 & 15.1 & $14.8-15.4$ \\
\hline Cesarean & 2839 & 15.4 & 1813 & 63.9 & $63.0-64.8$ \\
\hline \multicolumn{6}{|c|}{ Time of initiation of first breastfeeding ${ }^{c}$} \\
\hline After 1 hour & 10,788 & 58.5 & 2518 & 23.3 & $22.9-23.7$ \\
\hline Within first hour & 7639 & 41.5 & 1654 & 21.7 & $21.2-22.2$ \\
\hline \multicolumn{6}{|l|}{ Feeding infant } \\
\hline Exclusive breastfeeding & 12,752 & 69.2 & 1877 & 14.7 & $14.4-15.0$ \\
\hline Predominant breastfeeding & 5675 & 30.8 & 2295 & 40.4 & $39.7-41.1$ \\
\hline Total & 18,427 & 100.0 & 4172 & 22.6 & $22.3-22.9$ \\
\hline
\end{tabular}

Note:

a - Confidence interval;

b-Standard deviation;

c-Data missing for some participants.

infection), which were mutually exclusive. The analysis of statistical data was performed using Excel (Microsoft Corp., Redmond, WA, USA). Results are expressed as median (range), mean standard deviation for continuous variables, and number and corresponding percentage for qualitative variables. The primary end point was the epidemiology of the postpartum mastitis. Comparisons were undertaken using Student's t-test and Pearson's chisquared test or Fisher's exact test for categorical variables as appropriate. Statistical significance was defined as $P<0.05$.

\section{RESULTS}

During the study period (January 1st, 2015 and December 31st, 2017), 4,172 of 18,427 breastfeeding women's were found to have breast infections. The incidence of postpartum mastitis was $22.6 \%$ [95\% CI 22.3\%, 22.9\%]. Among these patients, $11.6 \%(484 / 4,172)$ breast abscess and $88.4 \%$ $(3,688 / 4,172)$ mastitis were observed.

The postpartum mastitis rates were $91.4 \%(3,813 / 4,172)$ is community-acquired and $8.6 \%(359 / 4,172)$ healthcare-associated infection. Healthcare-associated breast abscess was not been identified. Of the total cases breast infections, $74.8 \%(3,122 / 4,172)$ were detected after hospital discharge. For these post-discharge infections, $75.8 \%$ of patients did not return to the hospital where they delivered for evaluation or treatment.
The age of the patients was $\leq 18$ to $\geq 45$ years. Mean cohort age was 25.2 years (standard deviation (SD) 5.5 years), $37.4 \%(6,892 / 18,427)$ were primiparous. Postpartum mastitis rate was highest in the age group of $\leq 18$ years $(36.8 \% ; 321 / 872)$ followed by those in the age group of $\geq 45$ years $(33.5 \% ; 156 / 465)$ (Table 1$)$. All of the mothers were breastfeeding at recruitment, and 30.8\% reported providing prelacteal feeds to their newborn infants. Table 1 shows the characteristics data of patients with postpartum mastitis. A total of $22.6 \%$ [95\% CI, $22.3 \%, 22.9 \%]$ breastfeeding womens detected at least one episode of mastitis were observed in the postpartum period. In addition, 33.8\% $(6,231 / 18,427)$ reported cracked nipples. Findings from logistic regression after accounting for duration of exposure showed that those women who provided prelacteal feeds to their newborn infants and who had delivered by cesarean section had a higher likelihood of mastitis.

In this study, a total of 4,172 milk samples from women suffering infectious mastitis were analyzed using culture-based methods. A total of 4,758 isolates from the mastitis milk samples were identified. In the present study, $1.3 \%(55 / 4,172)$ samples did not show any microbial growth. Aerobic gram-negative bacilli make up 50.5\% $(2,405 / 4,758)$ and $42.7 \%(2,033 / 4,758)$ gram-positive cocci from of all isolates. In this study, $12.3 \%$ breast infections were polymicrobial. The predominant pathogens were: 
Table II. Distribution of pathogens, detected of milk samples from breastfeeding women with mastitis in Ukraine (2015-2017)

\begin{tabular}{|c|c|c|c|c|c|c|}
\hline \multirow{3}{*}{ Microrganism } & \multirow{2}{*}{\multicolumn{2}{|c|}{$\begin{array}{l}\text { All isolates } \\
(n=4758)\end{array}$}} & \multicolumn{4}{|c|}{ Type of breast infections } \\
\hline & & & \multicolumn{2}{|c|}{ Mastitis } & \multicolumn{2}{|c|}{ Breast abscess } \\
\hline & $\mathbf{n}$ & $\%$ & $\mathbf{n}$ & $\%$ & $\mathbf{n}$ & $\%$ \\
\hline Aerobes & 4438 & 93.3 & 3814 & 92.8 & 624 & 96.6 \\
\hline Gram-positive cocci & 2033 & 42.7 & 1718 & 41.8 & 315 & 48.8 \\
\hline Staphylococcus aureus & 1121 & 23.6 & 910 & 22.1 & 211 & 32.7 \\
\hline Staphylococcus epidermidis & 510 & 10.7 & 488 & 11.9 & 22 & 3.4 \\
\hline Streptococcus spp. & 124 & 2.6 & 106 & 2.6 & 18 & 2.8 \\
\hline Enterococcus faecalis & 230 & 4.8 & 169 & 4.1 & 61 & 9.5 \\
\hline Enterococcus faecium & 48 & 1.0 & 45 & 1.1 & 3 & 0.5 \\
\hline Gram-negative bacilli & 2405 & 50.5 & 2096 & 51.0 & 309 & 47.8 \\
\hline Escherichia coli & 922 & 19.4 & 870 & 21.2 & 52 & 8.0 \\
\hline Enterobacter spp. & 566 & 11.9 & 486 & 11.8 & 80 & 12.4 \\
\hline Klebsiella spp. & 416 & 8.7 & 324 & 8.3 & 92 & 14.2 \\
\hline Proteus mirabilis & 220 & 4.6 & 152 & 3.7 & 68 & 10.5 \\
\hline Pseudomonas aeruginosa & 228 & 4.8 & 216 & 5.3 & 12 & 1.9 \\
\hline Acinetibacter spp. & 53 & 1.1 & 48 & 1.2 & 5 & 0.8 \\
\hline Anaerobes & 198 & 4.2 & 185 & 4.5 & 13 & 2.0 \\
\hline Bacteroides spp. & 124 & 2.6 & 115 & 2.8 & 9 & 1.4 \\
\hline Other & 74 & 1.6 & 70 & 1.7 & 4 & 0.6 \\
\hline Fungi & 122 & 2.6 & 118 & 2.9 & 4 & 0.6 \\
\hline Candida albicans & 95 & 2.0 & 91 & 2.2 & 4 & 0.6 \\
\hline Other & 27 & 0.6 & 27 & 0.7 & 0 & 0 \\
\hline Total microorganisms & 4758 & 100.0 & 4112 & 100.0 & 646 & 100.0 \\
\hline
\end{tabular}

Staphylococcus aureus (23.6\%), Escherichia coli (19.4\%), Enterobacter spp. (11.9\%), Staphylococcus epidermidis (10.7\%), Klebsiella spp. (8.7\%), Pseudomonas aeruginosa (4.8\%), Enterococcus faecalis (4.8\%), and Proteus mirabilis (4.6\%). They are closely followed by streptococci (2.6\%), Bacteroides spp. (2.6\%), Candida albicans (2.0\%), Acinetibacter spp. (1.1\%), and Enterococcus faecium (1.0\%). The distribution of the microorganisms differed according to the breast abscess or mastitis (Table 2).

In mastitis patients, increased proportions of aerobic bacteria were observed with increased proportions of $E$. coli $(19.4 \%$ vs. $8.0 \%$ in breast abscess patients; $P<0.01)$, S. epidermidis ( $11.9 \%$ vs. $3.4 \%$ in breast abscess patients; $P<0.01$ ), and $P$. aeruginosa strains $(5.3 \%$ vs. $9 \%$ in breast abscess patients; $P<0.01)$. Conversely, decreased proportions of Klebsiella spp. (8.3\% vs. $14.2 \%$ in breast abscess infection, $P<0.05)$ and $P$. mirabilis were observed in mastitis patients $(3.7 \%$ vs. $10.5 \%$ in breast abscess infection, $P<0.01)$, and $E$. faecalis were observed in mastitis patients $(4.1 \%$ vs. $9.5 \%$ in breast abscess infection, $P<0.02)$. When taking into account prior antibiotic therapy, we did not observe any change in the type or proportion of the cultured organisms, whatever the type of infection. The predominant pathogens in healthcare-associated mastitis were: S. aureus, E.coli, Enterobacter spp., Klebsiella spp., P. aeruginosa, and E.faecalis.
The antibiotic susceptibility profiles of isolates from the infectious mastitis milk samples are presented in Table 3 and Table 4 . The staphylococcal isolates displayed a remarkable resistance to penicillin (87.3\%) and erythromycin (68.6\%), although there were some differences depending on the species (Table 3 ).

S. aureus isolates showed susceptibility (>90\%) to most of the other antimicrobials (tobramycin, nitrofurantoin, chloramphenicol, fosfomycin, levofloxacin, ciprofloxacin, gentamycin) tested, while these isolates ones exhibited a noticeable percentage of resistance against benzylpenicillin $(81.7 \%)$, erythromycin (65.7\%), ceftriaxone (26.6\%), and cefoxitin (26.3\%). No strains resistant to linezolid, teicoplanin, vancomycin, tigecycline, and fusidic acid were found. Methicillin-resistance was observed in 27.9\% of $S$. aureus (MRSA). Of the total MRSA strains, $74.8 \%$ is community-acquired, were detected after hospital discharge. S. epidermidis isolates demonstrated remarkable resistance to benzylpenicillin (92.9\%) and erythromycin (71.5\%), and moderate resistance to fusidic acid (41.4\%), mupirocin (28.7\%), cefoxitin (23.6\%). Most of this species isolates were susceptible to the rest of the antimicrobials. Methicillin-resistance was observed in $24.3 \%$ of S. epidermidis (MRSE). Of the total methicillin-resistance strains, $82.1 \%$ of MRSE is community-acquired, were detected after hospital discharge. Antimicrobial susceptibility tests were 
Table III. Antibiotic susceptibility (\%) of aerobic Gram-positive bacteria isolated from milk samples from breastfeeding women with mastitis in Ukraine (2015-2017).

\begin{tabular}{|c|c|c|c|c|c|c|c|c|}
\hline \multirow[t]{2}{*}{ Antibiotic } & \multicolumn{2}{|c|}{$\begin{array}{l}\text { S. aureus } \\
(n=140)\end{array}$} & \multicolumn{2}{|c|}{$\begin{array}{l}\text { S.epidermidis } \\
\quad(n=140)\end{array}$} & \multicolumn{2}{|c|}{$\begin{array}{l}\text { Streptococcus spp. } \\
(\mathrm{n}=\mathbf{2 2 0})\end{array}$} & \multicolumn{2}{|c|}{$\begin{array}{l}\text { E. faecalis } \\
(n=112)\end{array}$} \\
\hline & $\mathbf{S}$ & $\mathbf{R}$ & $\mathbf{S}$ & $\mathbf{R}$ & $\mathbf{S}$ & $\mathbf{R}$ & $\mathbf{S}$ & $\mathbf{R}$ \\
\hline Penicillin & 18.6 & 81.7 & 7.1 & 92.9 & 36.3 & 63.7 & 82.9 & 17.1 \\
\hline Ampicillin & 89.9 & 10.1 & 97.1 & 2.9 & 48.5 & 51.5 & 92.3 & 7.7 \\
\hline Oxacillin & 72.1 & 27.9 & 75.7 & 24.3 & NT & NT & NT & NT \\
\hline Cefuroxime & 89.9 & 16.1 & 78.6 & 21.4 & 95.2 & 4.8 & 0 & 100.0 \\
\hline Cefotaxime & 81.4 & 18.6 & 89.9 & 10.1 & 85.2 & 14.8 & NT & NT \\
\hline Ceftriaxone & 73.4 & 26.6 & 80.4 & 19.6 & 86.3 & 13.7 & NT & NT \\
\hline Imipenem & NT & NT & NT & NT & NT & NT & 100.0 & 0 \\
\hline Gentamycin & 90.9 & 9.1 & 94.7 & 5.3 & 94.1 & 5.9 & 83.3 & 16.7 \\
\hline Tobramycin & 98.6 & 1.4 & 100.0 & 0 & 98.9 & 1.9 & 76.9 & 23.1 \\
\hline Ciprofloxacin & 94.8 & 15.2 & NT & NT & NT & NT & 92.3 & 7.7 \\
\hline Levofloxacin & 98.6 & 1.4 & 94.1 & 5.9 & 88.0 & 12.0 & 92.9 & 7.1 \\
\hline Erythromycin & 34.3 & 65.7 & 28.5 & 71.5 & 31.3 & 68.7 & 15.1 & 84.9 \\
\hline Clindamycin & 89.9 & 10.1 & 78.6 & 21.4 & 89.9 & 16.1 & 7.3 & 92.7 \\
\hline Linezolid & 100.0 & 0 & 100.0 & 0 & 99.8 & 0.2 & 100.0 & 0 \\
\hline Teicoplanin & 100.0 & 0 & 97.7 & 2.3 & NT & NT & 92.9 & 7.1 \\
\hline Vancomycin & 100.0 & 0 & 99.5 & 0.5 & NT & NT & 91.3 & 8.7 \\
\hline Tigecycline & 100.0 & 0 & 95.2 & 4.8 & 69.2 & 30.8 & 100.0 & 0 \\
\hline Nitrofurantoin & 98.9 & 1.9 & 100.0 & 0 & NT & NT & 92.3 & 7.7 \\
\hline Chloramphenicol & 98.6 & 1.4 & 97.5 & 2.5 & NT & NT & 100.0 & 0 \\
\hline Fosfomycin & 97.1 & 2.9 & 93.1 & 6.9 & NT & NT & NT & NT \\
\hline Fusidic acid & 100.0 & 0 & 58.6 & 41.4 & NT & NT & NT & NT \\
\hline Mupirocin & 86.3 & 13.7 & 71.3 & 28.7 & NT & NT & NT & NT \\
\hline Rifampicin & 81.4 & 18.6 & 99.8 & 0.2 & 86.3 & 13.7 & 87.5 & 12.5 \\
\hline TMP-SMZ & 88.9 & 11.1 & 86.3 & 13.7 & NT & NT & 1.4 & 98.6 \\
\hline Cefoxitin & 73.7 & 26.3 & 76.4 & 23.6 & NT & NT & NT & NT \\
\hline
\end{tabular}

Note:

$\mathrm{R}$, resistant isolates (\%); S, susceptible isolates (\%); NT, no tested; TMP-SMZ, trimethoprim-sulfamethoxazole.

performed on a total of 220 streptococcal isolates and the results are summarized in Table 3. Streptococcal isolates demonstrated a noteworthy resistance against erythromycin (68.7\%) and benzylpenicillin (63.7\%), followed by ampicillin (51.5\%) and tigecycline (30.8\%). Most of the isolates were sensitive to rifampicin $(86.3 \%)$, clindamycin $(89.9 \%)$, gentamycin $(94.1 \%)$, cefuroxime $(95.2 \%)$, tobramycin (98.9\%), and linezolid (99.8\%). Regarding the genus Enterococcus, E. faecalis isolates $(\mathrm{n}=112)$ were not sensitive to those antibiotics to which they are intrinsically resistant (cefuroxime, clindamycin, and trimethoprim-sulfamethoxazole) (Table 3 ) and $84.9 \%$ of them were resistant to erythromycin. Approximately, $20 \%$ of the E. faecalis isolates displayed resistance to high levels of aminoglycosides (gentamycin, tobramycin) and around $7.5 \%$ was resistant to quinolones (ciprofloxacin and levofloxacin), and $8 \%$ to glycopeptides (vancomycin and teicoplanin). Vancomycin resistance was observwd in $8.7 \%$ of isolated enterococci (VRE). Antimicrobial susceptibility tests were performed on a total of 922 E. coli isolates. E.coli was most sensitive ( $>90 \%)$ to ertapenem (100\%), cefotaxime $(99.1 \%)$, ceftazidime (99.4\%), cefepime (99.3\%), fosfomycin (98.7\%), imipenem $(98.9 \%)$, piperacillin/tazobactam $(97.3 \%)$, and gentamycin $(94.5 \%)$ but least susceptibility $(<70 \%)$ was observed for moxifloxacin (54.2\%), cefuroxime (61.8\%), amoxicillin (65.2\%), and levofloxacin (67.3\%). Resistance to third-generation cephalosporins was observed in $9.1 \%$ E.coli isolates. No strains resistant to ertapenem were found. Enterobacter spp. was most sensitive (>90\%) to ciprofloxacin (98.6\%), piperacillin/tazobactam $(96.5 \%)$, cefotaxime (96.1\%), ceftazidime (96.2\%), ticarcillin (92.7\%), fosfomycin (92.6\%), amikacin (92.7\%), and gentamycin $(92.7 \%)$. No strains resistant to cefepime, imipenem, and ertapenem were found. Enterobacter spp. isolates ones 
Table IV. Antibiotic susceptibility (\%) of aerobic Gram-negative bacteria isolated from milk samples from breastfeeding women with mastitis in Ukraine (2015-2016).

\begin{tabular}{|c|c|c|c|c|c|c|c|c|c|c|}
\hline \multirow[t]{2}{*}{ Antibiotic } & \multicolumn{2}{|c|}{$\begin{array}{c}\text { E. coli } \\
(n=922)\end{array}$} & \multicolumn{2}{|c|}{$\begin{array}{l}\text { Enterobacter spp. } \\
\qquad(n=566)\end{array}$} & \multicolumn{2}{|c|}{$\begin{array}{c}\text { Klebsiella spp. } \\
(\mathrm{n}=416)\end{array}$} & \multicolumn{2}{|c|}{$\begin{array}{l}\text { P. mirabilis } \\
(n=220)\end{array}$} & \multicolumn{2}{|c|}{$\begin{array}{c}\text { P. aeruginosa } \\
(\mathrm{n}=\mathbf{2 2 8})\end{array}$} \\
\hline & $\mathbf{S}$ & $\mathbf{R}$ & $\mathbf{S}$ & $\mathbf{R}$ & $\mathbf{S}$ & $\mathbf{R}$ & $\mathbf{S}$ & $\mathbf{R}$ & $\mathbf{S}$ & $\mathbf{R}$ \\
\hline Amoxicillin & 65.2 & 34.8 & NT & NT & NT & NT & 71.4 & 28.6 & NT & NT \\
\hline AMC & 78.1 & 21.9 & 39.8 & 60.2 & 85.2 & 14.8 & 84.3 & 15.7 & NT & NT \\
\hline SAM & NT & NT & 38.1 & 61.9 & 68.7 & 31.3 & NT & NT & NT & NT \\
\hline Ticarcillin & 69.9 & 30.1 & 92.7 & 7.3 & NT & NT & 86.5 & 13.5 & 81.9 & 18.1 \\
\hline TZP & 97.3 & 2.7 & 96.5 & 3.5 & 100.0 & 0 & 100 & 0 & 88.2 & 11.8 \\
\hline Cefuroxime & 61.8 & 38.2 & 77.4 & 22.6 & 88.7 & 11.3 & NT & NT & NT & NT \\
\hline Cefotaxime & 99.1 & 0.9 & 96.1 & 3.9 & 97.3 & 2.7 & 98.8 & 1.2 & NT & NT \\
\hline Ceftriaxone & 74.2 & 25.8 & 65.9 & 34.1 & 78.9 & 21.1 & NT & NT & NT & NT \\
\hline Ceftazidime & 99.4 & 0.6 & 96.2 & 3.8 & 97.5 & 2.5 & 94.5 & 5.5 & 87.8 & 12.2 \\
\hline Cefepime & 99.3 & 0.7 & 100.0 & 0 & 77.6 & 22.4 & 96.7 & 3.3 & 51.2 & 48.8 \\
\hline Imipenem & 98.9 & 1.1 & 100.0 & 0 & 94.7 & 5.3 & 99.3 & 0.7 & 88.6 & 11.4 \\
\hline Meropenem & NT & NT & NT & NT & NT & NT & NT & NT & 96.8 & 3.2 \\
\hline Ertapenem & 100.0 & 0 & 100.0 & 0 & 100 & 0 & 100 & 0 & 100.0 & 0 \\
\hline Gentamycin & 94.5 & 5.5 & 91,2 & 8.8 & 91.2 & 8.8 & 98.8 & 1.2 & 63.8 & 36.2 \\
\hline Amikacin & 89.4 & 10.6 & 92.7 & 7.3 & 82.6 & 17.4 & 100.0 & 0 & 84.7 & 15.3 \\
\hline Ciprofloxacin & 87.2 & 12.8 & 98.6 & 1.4 & 95.1 & 4.9 & 75.1 & 24.9 & 81.2 & 18.8 \\
\hline Levofloxacin & 67.3 & 32.7 & 78.7 & 21.3 & 92.7 & 7.3 & NT & NT & NT & NT \\
\hline Moxifloxacin & 54.2 & 45.8 & 87.4 & 12.6 & 46.3 & 53.7 & NT & NT & NT & NT \\
\hline Cefoperazone & NT & NT & NT & NT & NT & NT & NT & NT & 66.2 & 33.8 \\
\hline Fosfomycin & 98.7 & 1.3 & 92.6 & 7.4 & 88.2 & 11.8 & NT & NT & 78.1 & 21.9 \\
\hline
\end{tabular}

Note:

$\mathrm{R}$, resistant isolates (\%); S, susceptible isolates (\%); NT, no tested; AMC, amoxicillin/clavulanic acid; SAM, ampicillin/sulbactam; TZP, piperacillin/tazobactam.

exhibited a noticeable percentage of resistance against ampicillin/sulbactam (61.9\%), amoxicillin/clavulanic acid (60.2\%), and ceftriaxon (34.1\%). Klebsiella spp. isolates showed susceptibility $>90 \%$ to most of the other antimicrobials (cefotaxime, ceftazidime, imipenem, levofloxacin, ciprofloxacin, gentamycin) tested, while these isolates ones exhibited a noticeable percentage of resistance against moxifloxacin (53.7\%), ampicillin/sulbactam (31.3\%), cefepime $(22.4 \%)$, and ceftriaxone $(21.1 \%)$. No strains resistant to piperacillin/tazobactam and ertapenem were found. Resistance to third-generation cephalosporins was observed in $8.8 \%$ Klebsiella spp. isolates. P. mirabilis was most sensitive (>90\%) to imipenem (99.3\%), gentamycin (98.8\%), cefotaxime (98.8\%), cefepime (96.7\%), and ceftazidime (94.5\%). No strains resistant to piperacillin/ tazobactam, ertapenem, and amikacin were found. $P$. aeruginosa isolates demonstrated remarkable resistance to cefepime (48.8\%), gentamycin (36.2\%), and cefoperazone (33.8\%), and was most sensitive to meropenem (96.8\%), imipenem (88.6\%), piperacillin/tazobactam (88.2\%), ceftazidime (87.8\%), amikacin (84.7\%), ticarcillin (81.9\%), ciprofloxacin (81.9\%). Carbapenem resistance was identified in $7.3 \%$ of P.aeruginosa isolates. No strains resistant to ertapenem were found.

\section{DISCUSSION}

To our knowledge this is the first epidemiological study for postpartum infectious mastitis among lactating women in Ukraine. During the study period, $22.6 \%$ breastfeeding women's were found to have breast infections. Among these patients, $11.6 \%$ breast abscess and $88.4 \%$ mastitis were observed. Of the total cases breast infections, $74.8 \%$ were detected after hospital discharge. The rate of healthcare-associated mastitis was $8.6 \%$. Healthcare-associated breast abscess was not been identified. In this study, $12.3 \%$ breast infections were polymicrobial. The predominant pathogens were: S. aureus (23.6\%), E. coli (19.4\%), Enterobacter spp. (11.9\%), S. epidermidis (10.7\%), Klebsiella spp. (8.7\%), P. aeruginosa (4.8\%), E. faecalis (4.8\%), and P. mirabilis (4.6\%). The overall proportion of methicillin-resistance in S. aureus (MRSA) was $27.9 \%$. Of the total MRSA strains, $74.8 \%$ is community-acquired, were detected after hospital discharge. Vancomycin resistance was observwd in 9.2\% of isolated enterococci (VRE). Carbapenem resistance was identified in $7.3 \%$ of P.aeruginosa isolates. Resistance to third-generation cephalosporins was observed in $8.8 \%$ Klebsiella spp. and E.coli $9.1 \%$ isolates.

Postpartum infectious mastitis is a common condition of women during lactation, although its incidence may be 
underestimated because of differences in case definition. and reporting [6, 12-14]. Previous studies have reported the incidence of postpartum mastitis to be as high as $33 \%$ in lactating women $[2,6-14]$. The majority of cases occur in the first eight weeks (two months) postpartum, but mastitis can occur at any time during breastfeeding $[2,13-16]$. The time of occurrence is an important consideration when measuring the incidence of mastitis, and several studies have reported that the incidence is highest in the first few weeks postpartum $[14,15]$ and that rates decline thereafter. In our study the follow-up of each breastfeeding women was continued 1 month (the first 4 weeks). During these period 22.6\% infectious mastitis were observed.

Infective mastitis that is usually associated with lactation can progress to a breast abscess $[1,2]$. Estimates, incidence of breast abscess may vary between $3 \%[2,8]$ and $11 \%[13$, 17], depending on the definition and length of postpartum follow-up. In our study $11.6 \%$ breast abscess were observed. All cases of breast infections were detected after hospital discharge.

Breast infections (and up to $40 \%$ of breast abscesses) may be polymicrobial, with isolation of aerobes (Gram-positive cocci and Gram-negative bacilli) and anaerobes $[18,19]$. In our study the bacterial spectrum observed in patients with postpartum mastitis matches the previous reports. Infectious mastitis is a common reason for antibiotic treatment in lactating women [4.]. Previous studies have reported high rates of antibiotic prescriptions for mastitis $[13,14]$. In the absence of antimicrobial susceptibility testing, the antibiotic treatment, leading to the increase of antimicrobial resistance among mastitis-causing agents $[7,20]$.

The estimates, Staphylococci are the most common pathogens causing agents of mastitis in breastfeeding women's [2, $4,5,18,21]$. However, there are limited studies reporting the antimicrobial susceptibility of Staphylococci isolates recovered from milk of women suffering mastitis [4]. The majority of staphylococci isolates are now methicillin-resistant $[5,19,21]$. In our study the overall proportion of methicillin-resistance was observed in $27.9 \%$ of S. aureus (MRSA) and $24.3 \%$ of S. epidermidis (MRSE). Of the total methicillin-resistance strains, $74.8 \%$ of MRSA and $82.1 \%$ of MRSE is community-acquired, were detected after hospital discharge. This finding parallels the local and national increases in MRSA reported in other infections.

The increasing resistance of Streptococcus spp. against penicillin, erythromycin and tetracycline has become a concerning issue in the clinical practice $[22,23]$. In our study streptococcal isolates demonstrated a noteworthy resistance against erythromycin $(68.7 \%)$ and penicillin (63.7\%), followed by ampicillin (51.5\%) and tigecycline (30.8\%). Marín M. et al. [4] showed high level resistance Enteroccoccus to aminoglycosides exhibited by about $20 \%$ of isolates, as well as the remarkable resistance to erythromycin $(86 \%)$, is in concordance with previous studies [24, 25]. It must also be addressed that about $7 \%$ of the E. faecalis isolates obtained in this study showed resistance to quinolones and vancomycin [4]. In our study, Enterococcus isolates were not sensitive to those antibiotics to which they are intrinsically resistant and $84.9 \%$ of them were resistant to erythromycin. Approximately, $20 \%$ of the E. faecalis isolates was resistance to high levels of aminoglycosides and around $7.5 \%$ was resistant to quinolones, and $8 \%$ to glycopeptides, is in concordance with previous studies [4]. Vancomycin resistance was observed in $8.7 \%$ of isolated enterococci (VRE). In the literature, the antimicrobial susceptibility patterns of aerobic Gram- negative bacteria isolated from milk samples from women with infectious mastitis have not been reported to date. In our study the predominant pathogens were E. coli, Enterobacter spp., Klebsiella spp., P.aeruginosa, and P.mirabilis. Carbapenem resistance was identified in $7.3 \%$ of P.aeruginosa isolates. Resistance to third-generation cephalosporins was observed in $8.8 \%$ Klebsiella spp. and E.coli 9.1\% isolates.

The WHO recommends emptying the breast by frequent breastfeeding or expressing, and our study found that most of the women's had received advice to this effect, which they were following. However, a small proportion of women had stopped breastfeeding as a result of their mastitis. We found that women's who reported providing prelacteal feeds to their newborn infants and who had delivered by cesarean section were more at risk of having an episode of mastitis (Table 1).

Our study is the first study reporting the incidence of postpartum mastitis in Ukraine. Strengths of our study include the cohort design, capturing all breastfeeding women's the study period, and near-complete microbiologic evaluation of clinical mastitis and antimicrobial testing of responsible pathogens. In our study population, the screening of hospital and ambulatory records was a sensitive surveillance method for identifying postpartum mastitis.

The limitations of this study include its retrospective design and conduct at a $45.8 \%$ regional hospitals (11 from 24) in Ukraine. The results may not be representative of other regions of Ukraine with different distributions of antimicrobial resistance of responsible pathogens of postpartum mastitis. This investigation provides valuable data as a first study for national surveillance of postpartum mastitis and potential comparison with data from other countries.

\section{CONCLUSIONS}

Mastitis in the breastfeeding women in Ukraine requires medical attention it is common, and a lot of cases are caused by pathogens resistant to antibiotics. The most infections occur after hospital discharge. Use of information collected from hospital and ambulatory records allows efficient identification of women who are very likely to have postpartum mastitis. Knowledge about local data of resistance may contribute to limiting resistance and may have a significant role in designing effective antimicrobial stewardship policies. Optimizing the management and empirical antimicrobial therapy may reduce the burden of mastitis, but prevention is the key element. 


\section{REFERENCES}

1. Irusen H., Rohwer A.C., Steyn D.W. et al. Treatments for breastabscesses in breastfeeding women. Cochrane Database of Systematic Reviews 2015, Issue 8. Art. No.: CD010490. D0l: https://doi.org/10.1002/14651858. CD010490.pub2.

2. Amir L.H. Academy of Breastfeeding Medicine Protocol Committee. ABM clinical protocol \#4: Mastitis, revised March 2014. Breastfeed Med. 2014;9(5):239-43. D0l: https://doi.org/10.1089/ bfm.2014.9984.

3. Boakes E., Woods A., Johnson N. et al. Breast Infection: A Review of Diagnosis and Management Practices. Eur J Breast Health. 2018;14(3):136-143. D0l: https://doi.org/10.5152/ejbh.2018.3871.

4. Marín M., Arroyo R., Espinosa-Martos et al. Identification of Emerging Human Mastitis Pathogens by MALDI-TOF and Assessment of Their Antibiotic Resistance Patterns. Front Microbiol. 2017;8:1258. D0I: https://doi.org/10.3389/fmicb.2017.01258.

5. Branch-Elliman W., Lee G.M., Golen T.H. et al. Health and economic burden of post-partum Staphylococcus aureus breast abscess. PLOS One. 2013 5;8(9):e73155. D0l: https://doi.org/10.1371/journal. pone.0073155.

6. Dalton E., Castillo E. Postpartum infections: A review for the non-OBGYN. Obstet Med. 2014; 7(3): 98-102. D0I: https://doi. org/10.1177/1753495X14522784.

7. Jahanfar S., $\mathrm{Ng}$ C.J., Teng C.L. Antibiotics for mastitis in breastfeeding women. Cochrane Database of Systematic Reviews 2013, Issue 2. Art. No.: CD005458. D0I: https://doi.org/10.1002/14651858.CD005458. pub3.

8. Amir L.H., Forster D., McLachlan H. et al. Incidence of breast abscess in lactating women: report from an Australian cohort. BJOG. 2004;111(12):1378-81. D0l: https://doi.org/10.1111/j.14710528.2004.00272.x

9. Salmanov A.G., Vdovychenko S.Y., Litus 0.I. et al. Prevalence of health care-associated infections and antimicrobial resistance of the responsible pathogens in Ukraine: Results of a multicenter study (2014-2016). Am J Infect Control. 2019;47(6):e15-e20. D0l:https:// doi.org/10.1016/j.ajic.2019.03.007.

10. Salmanov A., Vozianov S., Kryzhevsky V. et al. Prevalence of healthcareassociated infections and antimicrobial resistance in acute care hospitals in Kyiv, Ukraine. J Hosp Infect. 2019;102(4):431-437. D0I: https://doi. org/10.1016/j.jhin.2019.03.008.

11. Horan T.C., Andrus M., Dudeck M.A. CDC/NHSN surveillance definition of health care-associated infection and criteria for specific types of infections in the acute care setting. Am J Infect Control. 2008;36(5):30932. D0l: https://doi.org/10.1016/j.ajic.2008.03.002.

12. Spencer J.P. Management of mastitis in breastfeeding women. Am Fam Physician. 2008;78(6):727-31.

13. Foxman B., D'Arcy H., Gillespie B. et al. Lactation mastitis: occurrence and medical management among 946 breastfeeding women in the United States. Am J Epidemiology. 2002;155(2):103-14. D0l: https:// doi.org/10.1093/aje/155.2.103.

14. Scott J.A., Robertson M., Fitzpatrick J. et al. Occurrence of lactational mastitis and medical management: a prospective cohort study in Glasgow. Int Breastfeed J.2008;3:21.D0l:https://doi.org/10.1186/17464358-3-21.

15. Amir L.H., Forster D.A., Lumley J. et al. A descriptive study of mastitis in Australian breastfeeding women: incidence and determinants. BMC Public Health. 2007;7:62. D0l: https://doi.org/10.1186/1471-24587-62.
16. Cullinane M., Amir L.H., Donath S.M. et al. Determinants of mastitis in women in the CASTLE study: a cohort study. BMC Fam Pract. 2015; 16:181. D0l: https://doi.org/10.1186/s12875-015-0396-5.

17. Marchant D.J. Inflammation of the breast. Obstet Gynecol Clinf North Am. 2002; 29(1):89-102. D0l: https://doi.org/10.1016/S08898545(03)00054-8.

18. Moazzez A., Kelso R.L., Towfigh S. et al. Breast abscess bacteriologic features in the era of community-acquired methicillin-resistant Staphylococcus aureus epidemics. Arch Surg. 2007;142:881-884. D01: https://doi.org/10.1001/archsurg.142.9.881.

19. Brook I. The aerobic and anaerobic microbiology of neonatal breast abscess. Journal of Pediatr Infect Dis. 1991;10:785-786. D0I: https:// doi.org/10.1097/00006454-199110000-00014.

20. Barlow J. Mastitis therapy and antimicrobial susceptibility: a multispecies review with a focus on antibiotic treatment of mastitis in dairy cattle. J Mammary Gland Biol Neoplasia. 2011; 16: 383-407. D01: https://doi.org/10.1007/s10911-011-9235-z.

21. Delgado S., García P., Fernández L. et al. Characterization of Staphylococcus aureus strains involved in human and bovine mastitis. FEMS Immunol Med Microbiol. 2011;62(2):225-35. D0l: https://doi. org/10.1111/j.1574-695X.2011.00806.x.

22. Bruckner L., Gigliotti F. Viridans group streptococcal infections among children with cancer and the importance of emerging antibiotic resistance. Semin Pediatr Infect Dis. 2006;17(3):153-60. D0I: https:// doi.org/10.1053/j.spid.2006.06.008.

23. Doern C.D., Burnham C.A. It's not easy being green: the viridans group streptococci, with a focus on pediatric clinical manifestations. J Clin Microbiol. 2010;48(11):3829-35.

24. Chakraborty A., Pal N.K., Sarkar S. et al. Antibiotic resistance pattern of Enterococci isolates from nosocomial infections in a tertiary care hospital in Eastern India. J Nat Sci Biol Med. 2015;6(2):394-7.

25. Osuka H., Nakajima J., Oishi T. et al. High-level aminoglycoside resistance in Enterococcus faecalis and Enterococcus faecium causing invasive infection: Twelve-year surveillance in the Minami lbaraki Area. J Infect Chemother 2016;22(1):61-3. D0l: https://doi.org/10.1016/j. jiac.2015.09.003.

This study was approved by the Shupyk National Medical Academy of Postgraduate Education, Ukraine.

\section{Acknowledgements:}

We would like to thank all the nurses and physicians who contributed to the prevalence surveys.

\section{Funding:}

This work was supported by the Ministry of Health of Ukraine.

\section{ORCID and contributionship:}

Aidyn G. Salmanov - 0000-0002-4673-1154 A,B,D,E,F

Serhii E. Savchenko - 0000-0003-3802-2187 B,D,F

Kyrylo Chaika - 0000-0003-1738-8796 ${ }^{\text {B,C,F }}$

Alla D. Vitiuk - $0000000305507196^{B, F}$

Iana Ruban - 0000-0002-5178-308X B,C,F

Olena A. Dyndar - 0000-0002-0440-0410 B,D,F

Dmytro Zhelezov - 0000-0002-0071-2644 ${ }^{B, E, F}$

Ludmila Vorobey - 0000-0002-8969-228X ${ }^{B, F}$

Liudmula M. Semeniuk - $0000000273547061^{\text {B,C,F }}$ 
Natalia V. Hetsko - 0000-0001-6040-3942 B,D,F

Olga V. Tsmur - 0000-0001-5311-6136 B,E,F

Lidiya V. Suslikova - 0000-0002-3039-6494 B,C,F

Tetiana R. Nykoniuk - 0000-0001-5813-3808 B,F

Yelizaveta Ye. Shunko - 0000-0002-4883-2549 B,F

Halyna V. Beketova - 0000-0002-1362-0060 B,E,F

Lyudmila V. Manzhula - 0000-0002-1504-5506 ${ }^{B, D, F}$

Valentyna V. Kurochka - 0000-0001-6800-310X B,F

Esmira R. Abbasova ${ }^{B, E, F}$

\section{Conflict of interest:}

The Authors declare no conflict of interest

\section{CORRESPONDING AUTHOR}

Aidyn G. Salmanov

Shupyk National Medical Academy of Postgraduate Education,

St. Dorohozhytska 9, 04112, Kyiv, Ukraine

tel: +380667997631

e-mail:mozsago@gmail.com

Received: 29.01 .2020

Accepted: 01.04 .2020

A - Work concept and design, B - Data collection and analysis, C - Responsibility for statistical analysis,

D-Writing the article, $\mathbf{E}$-Critical review, $\mathbf{F}$ - Final approval of the article 